\title{
Off-piste in practice: efficacy, awkward questions and the power of relationship
}

\section{Abi Berger}

General Practitioner, London, UK

Correspondence to

Dr Abi Berger,

clo journal@fsrh.org

Received 1 May 2017

Accepted 12 May 2017

Published Online First

15 June 2017
CrossMark

To cite: Berger A. J Fam

Plann Reprod Health Care

2017:43:237.
I've started asking awkward questions. I realise it's a bit risky sometimes - but awkward questions seem to generate interesting conversations and I find this can change the direction of travel in a consultation quite quickly. Sex is one thing I'm asking about more and it's amazing how many patients have said "thanks for asking" - men, as well as women. I think I've been around long enough and know my patients well enough to know when and how to ask. And it's older patients I'm talking to more about sex these days, not so much the younger ones who are more used to talking about sex when they come in about contraception.

I think I'd forgotten about the tendency for sex to change and come to mean different things during long-term relationships. But I've also been reminded that sexual relationships started in later life may look very different from those we start as younger adults. One woman I've known for 20 years has found new love in her 60 s, and while the emotional boost has been exciting (and scary, all at the same time) - it turns out to be her sex life which is in need of attention - and yet she hadn't felt comfortable about raising the issue with a general practitioner. She was one of the patients who thanked me for initiating the conversation.

A man in his late 60 s supporting his wife through the journey of breast cancer ruefully admitted sex wasn't really on the agenda at the moment but wishes it could be. After a brief chat he thanked me for offering him "the extra time". In fact he didn't get any extra time, but we certainly deviated off-piste from the usual medication review.

As traditional general practice slowly collapses under the weight of expectation, more is demanded of us, and the choice of working as itinerant locums becomes more appealing, I suspect it will be the opportunities for conversations like these that will be lost. And with what impact? On the face of it, possibly very little. But some people do look to nurture ongoing relationships with their family doctors, and these relationships and their continuity depend on a form of safe intimacy that is not created by modern-day general practice. My questions may feel a bit awkward, but to my mind they seem to foster an intimacy and a gratitude found nowhere else in my world of doctoring.

We're being urged to do whatever it takes to keep patients out of hospital. But it's not the creation of care plans but the continuity of relationship and knowledge accrued over time that will achieve this. It's an aspect of medicine that cannot be quantified or easily measured but which to my untutored eye holds more value than almost anything else. I may have 'off days' and feel stressed at times, but with a robust relationship between myself and my patients, such fluctuations are more likely to be forgiven and forgotten just as they are in any other relationship.

When I see a patient I have met a number of times over a period of years, the pattern of health issues becomes familiar and I can often short-circuit to the nub of the problem without the need to start from scratch each time. I'd like to think that referrals and even hospital admissions can sometimes be avoided.

My awkward questions feel more like conversational openers than tools for data collection. Not only do they help avoid the use of unnecessary resources, but the ensuing dialogue may ultimately help to move both patient and doctor on.

Competing interests None declared.

Provenance and peer review Commissioned; internally peer reviewed.

(C) Faculty of Sexual and Reproductive Healthcare of the Royal College of Obstetricians and Gynaecologists (unless otherwise stated in the text of the article) 2017. All rights reserved. No commercial use is permitted unless otherwise expressly granted. 